\title{
Recombinant human interferon alfa-2b treatment for acute non-A, non-B hepatitis
}

N C Tassopoulos, M G Koutelou, G Papatheodoridis, H Polychronaki, I Delladetsima, T Giannikakis, A Todoulos, A Toliopoulos, A Hatzakis

\begin{abstract}
To assess the safety and possible efficacy of recombinant human interferon alfa-2b in preventing the development of chronic hepatitis, 24 adults (eight men, 16 women) with acute non-A, non-B (NANB) hepatitis were recruited to a pilot study. Half of the cases were parenterally transmitted and half were community acquired. Twelve patients received 3 million units (MU) interferon three times weekly subcutaneously for six weeks and the remaining 12 patients received no treatment. Anti-hepatitis C virus (HCV) was detected in $14(58 \cdot 3 \%)$ of the 24 patients. The alanine aminotransferase activity returned to normal in nine of 12 interferon alfa-2b treated patients and six of 12 controls by week 52 . Interferon alfa-2b was well tolerated, even in jaundiced patients, who only complained of mild flu like syndrome during the first week of treatment. These data are consistent with the hypothesis that interferon alfa-2b may help prevent progression to chronic hepatitis (interferon alfa-2b 25\% $v$ controls $50 \%$ ), particularly in anti-HCV negative cases (interferon alfa-2b none of six $v$ controls two of four). A randomised, double blind placebo-controlled trial is required, however, to substantiate these results further.
\end{abstract}

(Gut 1993; supplement: S130-S132)

Liver Unit,
First Department of Medicine,

Western Attica

General Hospital,

Athens, Greece

N C Tassopoulos

M G Koutelou

G Papatheodoridis

T Giannikakis

A Todoulos

A Toliopoulos

Department of

Hygiene and

Epidemiology,

Athens University

Medical School,

Athens, Greece

H Polychronaki

A Hatzakis

Laboratory of

Pathology,

Laikon General

Hospital,

Athens, Greece

I Delladetsima

Correspondence to:

Dr N C Tassopoulos,

Liver Unit,

First Dept of Medicine,

Western Attica General

Hospital,

1 Dodecanissou Street,

Athens 12351, Greece.

Acute non-A, non-B (NANB) hepatitis is considered to be a mild disease with a tendency to progress to chronicity. Chronic hepatitis has been reported in $32-65 \%$ of patients with acute NANB hepatitis, irrespective of the risk factors involved. ${ }^{1-5}$ Development of chronic hepatitis is seen twice as frequently in anti-hepatitis $C$ virus (HCV) positive as in anti-HCV negative cases, and occurs in men more often than in women. ${ }^{6}$ No specific treatment for acute NANB hepatitis is available that fulfils the following treatment goals: (a) to ameliorate symptoms and improve quality of life; (b) to reduce social cost by shortening the duration of illness; (c) to reduce the incidence and severity of complications; (d) to prevent progression to chronic hepatitis; and (e) to reduce infectivity. Because of the antiviral action of alpha inteferon and its beneficial effects in chronic NANB/type C hepatitis, ${ }^{78}$ we assessed the safety and possible efficacy of recombinant human interferon alfa- $2 b$ in preventing the development of chronic hepatitis in patients with acute NANB/C hepatitis.

\section{Methods}

Twenty four Greek adults (eight men, 16 women) with acute NANB hepatitis took part. They were divided into two groups: group I consisting of 12 patients who received 3 million units (MU) of interferon alfa-2b (INTRON $A$, Schering Plough, Kenilworth, NJ) three times a week subcutaneously for six weeks and group II comprising 12 patients matched to group I for sex, age, and risk factors, but who received no treatment. The demographic features of these patients are shown in Table I. Blood samples were obtained weekly for the first month after treatment, twice weekly for the second month, every month for the next four months, and then every two months for the next six months.

The criteria for diagnosis of acute viral hepatitis were: symptoms and signs of hepatitis of less than one month's duration; peak serum alanine aminotransferase (ALT) activity equal to or greater than eight times the upper limit of normal (46 IU//); and exclusion of other possible causes of liver injury (for example preexisting liver disease, alcohol abuse, drugs, autoimmune hepatitis). Acute NANB hepatitis was defined by the absence of serological markers for acute hepatitis A (IgM antihepatitis A virus (HAV) negative), acute hepatitis B (hepatitis B surface antigen ( $\mathrm{HBsAg}$ ) negative and/or IgM anti-hepatitis B core $(\mathrm{HBc})$ negative), and acute Epstein-Barr virus infection (IgM antibody to Epstein-Barr virus capsid antigen negative). Progression to chronic hepatitis was characterised by raised ALT activity one year after the onset of the acute episode. ${ }^{5}$

Commercially available enzyme immunoassays (Abbott Labs, North Chicago, IL) were used for the detection of $\mathrm{HBsAg}, \operatorname{IgM}$ anti-HBc, and IgM anti-HAV. IgM antibody to the viral capsid antigen of Epstein-Barr virus was determined by indirect immunofluorescence. Ninety six serum specimens were tested for antibodies to hepatitis $\mathrm{C}$ virus (HCV) by Abbott's second generation enzyme immunoassay. This assay is based on recombinant $\mathrm{HCV}$ non-structural antigens derived from the NS4 (c100) and NS3 (33c) regions, and on a structural antigen derived from the $5^{\prime}$ region of the HCV genome (putative core). One or two repeatedly reactive samples per patient were confirmed by a second generation recombinant immunoblot 
TABLE I Demographic, biochemical, and serological features of 24 patients with acute non- $A$, non- $B$ hepatitis

\begin{tabular}{lcc}
\hline & Interferon alfa-2b & Controls \\
\hline No studied & 12 & 12 \\
Men/women & $4 / 8$ & $4 / 8$ \\
Age (SD) (y) & $46 \cdot 2(0 \cdot 9)$ & $50 \cdot 2(1 \cdot 5)$ \\
Risk factor: & & 6 \\
$\quad$ Transfusions & 5 & 0 \\
$\quad$ Needlestick injury & 1 & 6 \\
$\quad$ None (sporadic) & 6 & $1008 \cdot 7(524 \cdot 8)$ \\
Peak alanine aminotransferase (IU/l) & $1120 \cdot 1(333 \cdot 6)$ & $(467-2078)$ \\
$\quad$ (mean (SD)) & $(710-1808)$ & $10 \cdot 8(6 \cdot 0)$ \\
Peange) & & $(0 \cdot 9-18 \cdot 9)$ \\
$\quad$ (mean (SD)) & $12 \cdot 3(13 \cdot 5)$ & $8(67 \%)$ \\
(range) & $(0 \cdot 9-51 \cdot 6)$ & \\
Anti-HCV positive & $6(50 \%)$ &
\end{tabular}

*Occurring within six months before the onset of hepatitis.

assay (RIBA-2) (Ortho Diagnostic Systems, Raritan, NJ, USA). ${ }^{9}$

Liver tissue specimens were obtained from 11 patients with community acquired NANB hepatitis $24 \cdot 1(9 \cdot 4)$ days (range: 14-41) after the onset of hepatitis. All liver tissue samples were stained with haematoxylin and eosin, Van Gieson-Hansen, periodic acid Schiff after diastase treatment, and Gomori. Histological lesions were interpreted in accordance with internationally accepted criteria. ${ }^{10}$ The severity of acute hepatitis was classified as mild, moderate, or severe according to the extent and type of liver cell necrosis. Mild acute hepatitis was typified by small to moderate focal necrosis, moderate hepatitis by multiple focal and/or small confluent necrosis in zone 3, and severe hepatitis by large confluent necrosis in zone 3 and/or bridging necrosis with or without fibrosis. The presence of piecemeal necrosis, central-portal bridging necrosis, and bile duct lesions of the hepatic type suggested possible transition to chronic hepatitis. Extensive confluent and bridging necrosis suggested possible transition to cirrhosis.

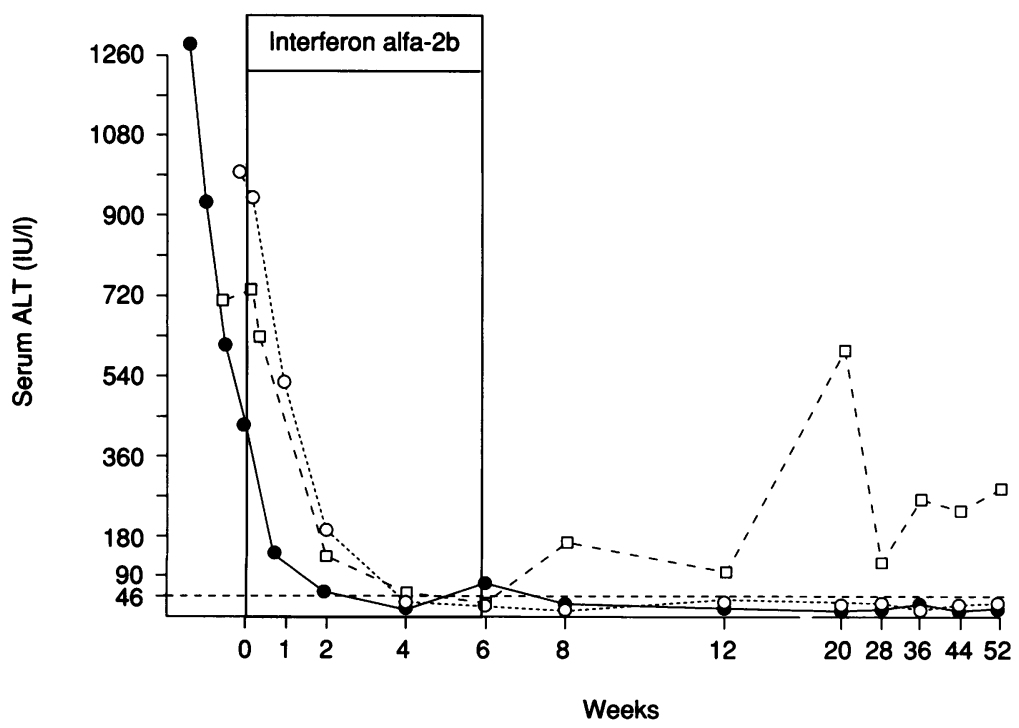

Figure 1 Three adult patients with acute non- $A$, non- $B$ hepatitis treated with $3 M U$ of interferon alfa-2b three times weekly for six weeks. Two patients had normal alanine aminotransferase (ALT) activities at the end of treatment (week six). One of these relapsed after stopping treatment and developed chronic hepatitis. The third patient had raised $A L T$ values at the end of week six. The ALT had returned to normal by week eight, however, and remained normal during follow up.

\section{Results}

The biochemical profile (peak ALT, peak bilirubin) before treatment was similar in the two groups of patients studied (Table I). Acute hepatitis was icteric (bilirubin $>34 \mu \mathrm{mol} / \mathrm{l}$ ) in $11(92 \%)$ patients randomised to interferon treatment and $11(92 \%)$ control patients. AntiHCV was detected in six $(50 \%)$ interferon alfa$2 \mathrm{~b}$-treated and eight $(67 \%)$ untreated patients. Anti-HCV appeared early (three to 30 days after the onset of hepatitis) in the serum of four treated and eight untreated subjects; two treated patients became seropositive for anti$\mathrm{HCV}, 41$ and 51 days respectively after the onset of hepatitis.

Histological lesions were classified as moderate in two and severe in four of the six interferon alfa-2b-treated community acquired cases of hepatitis. In contrast, lesions were classified as mild in one, moderate in three, and severe in one of the five untreated community acquired cases with a biopsy specimen available at the acute phase. Possible transition to chronic hepatitis and/or cirrhosis was observed in three of six interferon alfa-2b-treated and two of five control cases.

The ALT returned to normal in nine of 12 interferon alfa-2b-treated and three of 12 control patients at the end of treatment (week six). During follow up (week eight to week 52), the ALT returned to normal in three treated patients and three of the untreated patients who had abnormal enzyme activities at the end of week six. In contrast, three treated patients who had normal ALT values at the end of week six relapsed and developed chronic hepatitis; these patients were seropositive for anti-HCV. ALT changes in three treated and three control patients are shown in Figures 1 and 2, respectively. Anti-HCV remained detectable in all except one treated patient, who became seronegative seven months after anti-HCV seroconversion; this patient had self-limited hepatitis, and was the only case of anti-HCV seroreversion out of 117 anti-HCV positive patients included in the follow up study (Tassopoulos et al, unpublished data).

Progression of acute NANB hepatitis to chronic hepatitis was observed less frequently in treated anti-HCV negative patients (none of six $v$ two of four), men (one of four $v$ four of four), and in sporadic cases (none of six $v$ three of six) (Table II).

Interferon alfa-2b was well tolerated, even in jaundiced patients, who complained only of mild flu like syndrome during the first week of treatment. Neither leukopenia nor thrombocytopenia were observed, and none of the patients showed biochemical exacerbation or clinical deterioration of acute hepatitis during the six week treatment period.

\section{Discussion}

The study showed that interferon alfa- $2 b$ is safe and well tolerated, even in jaundiced patients with acute NANB/C hepatitis, and reconfirmed our previous findings in acute 


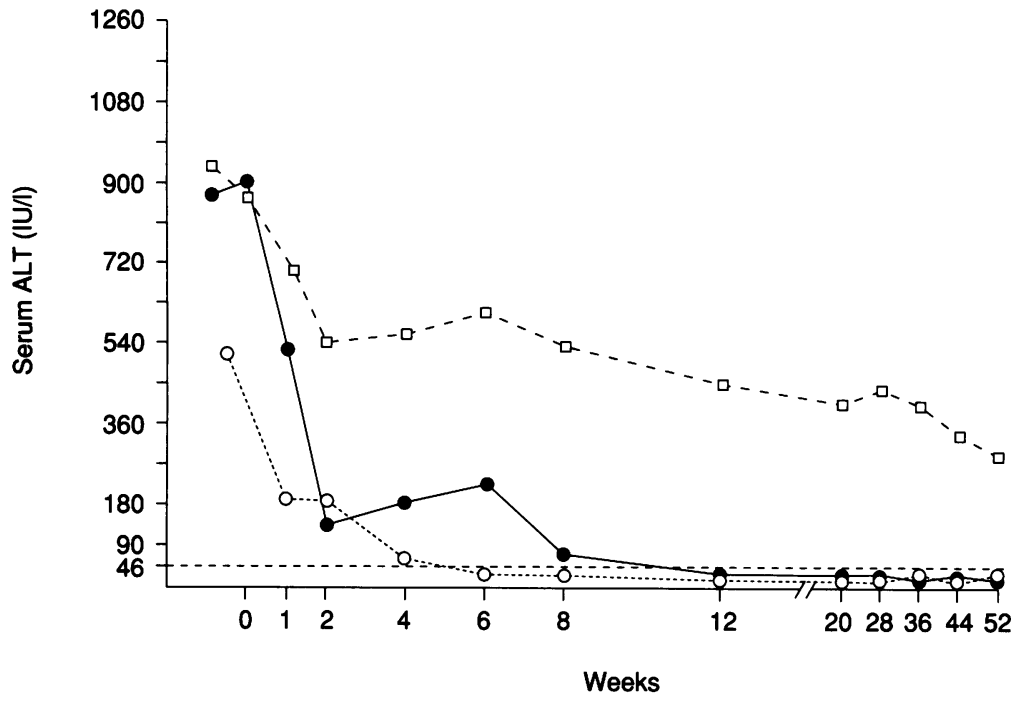

Figure 2 Serial determinations of alanine aminotransferase (ALT) activities in three untreated adults with acute non- $A$, non- $B$ hepatitis. The $A L T$ values returned to normal by the end of week six and eight, respectively, in two patients. The third patient developed chronic hepatitis and the ALT remained persistently abnormal.

TABLE II Progression of acute non- $A$, non- $B$ hepatitis to chronic hepatitis by treatment status during 52 weeks of follow up

\begin{tabular}{|c|c|c|c|c|}
\hline & \multicolumn{2}{|c|}{ Interferon alf $a-2 b$} & \multicolumn{2}{|c|}{ Controls } \\
\hline & No & $\%$ & No & $\%$ \\
\hline \multicolumn{5}{|c|}{ Anti-hepatitis $C$ virus } \\
\hline $\begin{array}{l}\text { Positive } \\
\text { Negative }\end{array}$ & $3 / 6$ & 50 & $4 / 8$ & 50 \\
\hline \multicolumn{5}{|l|}{ Sex: } \\
\hline Men & $1 / 4$ & 25 & $4 / 4$ & 100 \\
\hline Women & $2 / 8$ & 25 & $2 / 8$ & 25 \\
\hline \multicolumn{5}{|l|}{ Risk factor: } \\
\hline Transfusions & $3 / 6^{\star}$ & 50 & $3 / 6$ & 50 \\
\hline None & $0 / 6$ & 0 & $3 / 6$ & 50 \\
\hline Total & $3 / 12$ & 25 & $6 / 12$ & 50 \\
\hline
\end{tabular}

*One patient with a needlestick exposure was included; she developed chronic hepatitis.

hepatitis B. ${ }^{11}$ None of the 12 treated subjects showed flare up or deterioration of acute hepatitis during the six weeks' treatment with $3 \mathrm{MU}$ interferon three times weekly.

Progression to chronic hepatitis C did not seem to be modified by this low dose interferon alfa-2b treatment in anti-HCV positive patients (three of six $v$ four of eight), in contrast to recently published data from Japan. ${ }^{12}$ Interferon alfa-2b may be beneficial, however, in anti-HCV negative patients (none of six $v$ two of four), men, in sporadic cases, and in histologically severe acute hepatitis. A multivariate regression analysis of risk factors for chronic liver disease after acute NANB hepatitis showed that male sex, clinical parameters (clinical severity, early relapse), and histological severity of acute hepatitis were independent risk factors. ${ }^{13}$ It is of interest that treated patients had more severe histological features of acute hepatitis than controls, and this may have resulted in an underestimate of the efficacy of treatment in the between group comparisons.

A higher dose of interferon alfa-2b (for example, $5 \mathrm{MU}$ ) for a longer period of time may improve these preliminary results, particularly in anti-HCV positive patients. A randomised double blind placebo-controlled trial is necessary, however, to elucidate further the discrepancies in these results.

1 Alter HJ, Purcell RH, Feinstone SM, Tegtmeurier GE. Non-A, non-B hepatitis: its relationship to Non-A, non-B hepatitis: its relationship to indirect test methods. In: Szmuness W, Alter HJ, Maynard JE, eds. Viral hepatitis. Philadelphia: Franklin Maynard JE, eds. Viral hepatitis. Philadelphia: Franklin

2 Berman M, Alter HJ, Ishak KG, Purcell RH, Jones EA. The chronic sequelae of non-A, non-B hepatitis. Ann Intern Med 1979; 91: 1-6.

3 Sampliner RE, Woronow DI, Alter MJ, et al. Communityacquired non-A, non-B hepatitis: clinical characteristics and chronicity. $\mathcal{F}$ Med Virol 1984; 13: 125-30.

4 Nagata A, Kiyosawa K, Koike Y, et al. Epidemiology of sporadic acute non- $A$, non-B hepatitis in Japan: a comparison with hepatitis A and B. Am $\mathcal{f}$ Gastroenterol 1985; 80: 298-302.

5 Tassopoulos NC, Alikiotis M, Limotirakis F, Nikolakakis $P$, Mela H, Paraloglou-Ioannides M. Acute sporadic non-A, Mela H, Paraloglou-Ioannides M. Acute sporadic non-A,

6 Tassopoulos NC, Hatzakis A, Delladetsima I, Koutelou $M G$, Todoulos A, Miriagou V. Role of hepatitis $C$ virus in acute non-A, non-B hepatitis in Greece: a five-year prospective study. Gastroenterology 1992; 102: 969-72.

$7 \mathrm{Di}$ Bisceglie AM, Martin P, Kassianides C, et al. Recombinant interferon alfa therapy for chronic hepatitis C. A randomized, double-blind, placebo-controlled trial. N Engl F Med 1989; 321: 1506-10.

8 Davies GL, Balart LA, Schiff ER, et al. Treatment of chronic hepatitis $\mathrm{C}$ with recombinant interferon alfa. A multicenter randomized, controlled trial. $N$ Engl $f \mathrm{Med}$ 1989; 321: 1501-06.

9 van der Poel CL, Cuyper HTM, Reesnick HW, et al. Confirmation of hepatitis $\mathrm{C}$ infection by new four antigen recombinant assay. Lancet 1991; 337: 317-9.

10 Bianchi L, De Groote J, Desmet VJ, et al. Acute and chronic hepatitis revisited. Lancet 1977; ii: 914-19.

11 Tassopoulos NC, Hadziyannis SJ, Wright GE. A randomized double-blind placebo-controlled trial of $\alpha$-interferon in acute type B hepatitis. Hepatology 1989; 10: 576 .

12 Omata M, Yokosuka O, Takano S, et al. Resolution of acute hepatitis $\mathrm{C}$ after therapy with natural beta interferon. Lancet 1991; 338: 914-15.

13 Tassopoulos NC, Hatzakis A, Delladetsima I, et al. Risk factors influencing the outcome of acute non-A, non-B hepatitis (abstract). $\mathcal{F}$ Hepatol 1991; 13 (suppl 2): S75. 